\title{
EDITORIAL
}

\section{¿Es el plagio una sorpresa? ¿Acaso tiene clase?}

\author{
It is the plagiarism a surprise? Has it class?
}

Entendemos que no es posible abordar en un espacio editorial el vasto tema del plagio, sus implicaciones y temas conexos presente en libros, artículos científicos, historias, películas, frases, logotipos, inventos, marcas, colores de productos e ideas entre otros muchos temas desarrollados por el ser humano. Este mal es muy antiguo, pero parafraseando términos de los infectólogos, hoy día se encuentra en plena reemergencia. Al patógeno de esta epidemia le favorece indiscutiblemente la moderna vía de transmisión global que es el internet, ya que través de la red, el cibernauta dispone de toneladas de información; la mayoría gratuita.

Plagiar (Del lat. plagiāre), de acuerdo con el Diccionario de la Real Academia Española (1), es un verbo transitivo que significa, en la acepción académica que es la de nuestro interés, copiar en lo sustancial obras ajenas, dándolas como propias. Por otro lado, según el Diccionario Collins de la Lengua Inglesa (2), plagio es "el acto de plagiar" que significa apropiarse de ideas, pasajes, etc., de otro trabajo de un autor o autores. Además, se refiere al plagio explícitamente como un robo literario, en donde se roban o copian las palabras o ideas de alguien más y pasan él o ellos como si fueran los autores originales sin darle el respectivo crédito a la fuente de información.

La palabra plagio tiene aplicación en diversas y amplias situaciones en la sociedad. Una muy comentada en los claustros educativos es la relacionada con los estudiantes cuando ellos acceden al internet, identifican un artículo de su interés y aplican el famoso sistema de "copie, corte y pegue" para la realización de sus trabajos. De esta manera, pueden pegar recortes en "fila india", creando un documento extenso que entregan a sus profesores para su evaluación. Pero cuando se recurre a este fácil sistema que brinda la red, se observa entre otras cosas que generalmente no existen conectores gramaticales entre frases y párrafos; incluso, no hay ilación entre las ideas que se pretenden discutir o comentar. Adicionalmente, ellos eligen fuentes de información inadecuadas, lo que revela de inmediato este procedimiento ilícito. Lo que es peor, si los estudiantes tienen que sustentar oralmente el trabajo, se presentará una debacle, pues ellos no podrán responder con contundencia las preguntas formuladas por el profesor o por sus propios compañeros de clase. Esta conducta, en la mayoría de los casos, puede darse por desconocimiento del tema, así como de las normas que regulan esta materia; pero existe un grupo que está consciente que lo está realizando es francamente un plagio.

Con ligereza se podría pensar que la situación antes comentada es conducta exclusiva de los estudiantes. Pero, recordando apartes del coro de la mundialmente conocida canción "Pedro Navajas" del compositor, cantante, actor y político panameño, Rubén Blades, "la vida te da sorpresas, sorpresas te da la vida". Lo que significa en otras palabras que durante una búsqueda de referencias bibliográficas para plantear una hipótesis, soportar y discutir finalmente los resultados de una investigación, los cuales deben ser plasmados en un 
manuscrito para luego someterlo al Comité Editorial de una revista científica, encontramos autores con "investidura" de investigadores y con altos grados académicos que han caído en la fácil tentación de plagiar..."la vida te da sorpresas, sorpresas te da la vida".

De hecho, existen numerosos manuscritos disponibles que así lo confirman. Por mencionar algunos, recientemente Garner (3) informa que anualmente aparecen alrededor de 3.000 nuevas citas que son similares a las ya publicadas en la literatura biomédica, considerando solamente la base de datos Medline. Por otro lado, Errami et al (4) analizaron una muestra de 62.213 citas también en Medline y encontraron que el $0.04 \%$ fueron potenciales casos de plagio y el $1.35 \%$ correspondió a publicación duplicada.

A propósito del tema, nos permitimos citar textualmente el primer párrafo del artículo "Publicación Duplicada" de Rosa Sancho (5) adscrita al Instituto de Estudios Documentales sobre Ciencia y Tecnología -IEDCYT-. CSIC, el cual reza así: "La distorsión intencionada del método científico y de sus normas éticas se considera fraude científico, e incluye tanto las faltas graves delictivas (plagio, falsificación, modificación o invención de datos, o de los métodos empleados), como la mala práctica científica que supone la publicación repetida, total o parcial de un artículo ya publicado previamente en otra o en la misma revista, firmado por los mismos autores, pero sin conocimiento de los respectivos editores $y$, sobre todo, sin acreditar que se trata de un duplicado del original, es decir, con ánimo de engañar". Si bien existen numerosos artículos que pueden ser consultados sobre el tema, pensamos que en la introducción del artículo de la autora antes citada, quedó todo claro.

Dadas las circunstancias de la reemergencia epidémica del plagio en todas sus versiones y formas mutantes, existen hoy día herramientas informáticas disponibles tanto comerciales como gratuitas de software que permiten "vacunar" preventivamente a la población riesgo a fin de poder controlar una posible pandemia. Entendemos entonces que revisores y editores debemos adicionar obligatoriamente una herramienta más a nuestro trabajo en la búsqueda permanente de mejores estándares de la revista que dirigimos. No obstante, los editores de las revistas científicas, partimos de la buena fe de nuestros colegas y asumimos que su férrea ética está a prueba de plagio, lo que significa que podemos ser asaltados en nuestra confianza depositada en ellos, la mayoría, profesores universitarios.

En definitiva, el plagio es un crimen abominable contra la academia, la investigación y por supuesto contra los lectores que finalmente son los usuarios de la información y del nuevo conocimiento que se genera.

Marco González T. M.Sc.

Salim Mattar V. Ph.D.

\section{REFERENCIAS}

1. Real Academia Española. Plagiar [en línea]. URL disponible en: http://buscon. rae.es/draeI/SrvltConsulta?TIPO_ $\mathrm{BUS}=3 \& \mathrm{LEMA}=$ plagiar.

2. Hanks, P. Collins Dictionary of the English Language. London, Glasgow: William Collins; 1979.

3. Garner HR. Combating unethical publications with plagiarism detection services. Urol Oncol 2011; 29(1):95-9
4. Errami M, Hicks JM, Fisher W, Trusty D, Wren JD, Long TC, Garner HR. Déjà vu: a database of highly similar citations in the scientific literatura. Bioinformatics 2008; 24(2):243-9.

5. Sancho R. Publicación duplicada. [En línea]. Instituto de Estudios Documentales sobre Ciencia y Tecnología - IEDCYT-CSIC. 2008 URL disponible en: http://www. madrimasd.org/ informacionIdi/análisis/analisis/analisis. asp id $=36354$. 